\title{
Human resource management in multinational companies- from the perspective of Hilton Hotels
}

\author{
Ma Rui ${ }^{1}$ \\ ${ }^{1}$ School of Economics and Management, Beijing Jiaotong University, Beijing, China
}

\begin{abstract}
Under the background of globalization, multinational companies not only quantity increased obviously, but also plays a more and more important role in the world. In different cultural environments, it is very important for multinational companies to use human resource management effectively to promote their operation. By analyzing the current situation of human resource management of Hilton Hotels, this paper explored the universal management experience, hoping to provide reference for the development of China's multinational hotels.
\end{abstract}

\section{INTRODUCTION}

Global economic integration has intensified the increase in the number of multinational companies, however, not all of them can achieve success. In the daily management of multinational companies, human resources, as an invisible productivity, is one of the key factors restricting the development speed and level of companies. Due to the employees in multinational companies are come from diverse countries, and each branch of the company is set in different cities, which makes the demand of human resources of employees have obvious differences. This requires the human resource management of transnational companies to be more scientific and localized based on differences and development goals.

There are many modules involved in human resources, including recruitment, training, welfare system, salary standard, career planning and so on. Both the parent company and the host country have an impact on the human resource management mode of multinational corporations, in general, there are three kinds of modes: centralized, formalized and humanized. In brief, concentration means that the headquarters of a multinational corporation forces its subsidiaries to comply with uniform management standards. The essence of formalization is that multinational managers can carry out human resource management flexibly only in the local environment of host country. Humanized mode refers to the combination of localization and stylization. Through investigation, we found most of studies showed that organic management mode was more conducive to the development of transnational companies.

The existing literature mostly pointed out that the means of human resource management in multinational companies were constantly optimized, the specific promotion of people-oriented concept and cultural management have always been the focus of attention, and information management has been the hot spot in recent years. Nevertheless, there are few articles that comprehensively analyze the human resource management methods of multinational firms, so it is difficult to understand the management structure of a certain company or industry.

All in all, previous literature had been explored that multinational companies raised human resource management to strategic position and put forward corresponding management measures. As one of the important service industries, hotel industry plays an important role in the development of real economy. However, there is still a lack of research on human resources of hotels, especially multinational hotels. Therefore, we choose the excellent international brand Hilton Hotel for analysis, and summarize the specific and feasible human management means for reference.

\section{HUMAN RESOURCE MANAGEMENT IN HILTON HOTELS}

Hilton Hotels is a multinational hotel founded by Conrad Hilton in 1919, headquartered in the United Kingdom. Hilton hotels is now one of the largest hotels in the world and located in major cities on six continents. The opening of Hilton Shanghai in 1988 marked Hilton entry into the Chinese market. Over the years, Hilton has adhered to the people-oriented management philosophy, treated employees with respect and equality, and won the title of the best Multinational Workplace in Asia in 2018.

\section{A. Recruitment}

As a hotel service industry, Hilton's staff are characterized by youth, the proportion of workers under 25 years old is even as high as $80 \%$ (Fig. 1), and its management personnel are generally bachelor degree or above. On this 
basis, Hilton has the following five recruitment channels: internal application, internal recommendation, campus recruitment, headhunting company recommendation and online recruitment. In order to retain talents as much as possible, Hilton headquarters has a Talent Bank with constantly updated information, which involves thousands of key people (assistant managers and above). If there is a new management position, the hotel will consider to be screened in this list first, and internal promotion can meet the demand of $5 \%$ of new positions. Employees are encouraged to apply and are also welcomed to be recommended by other hotel staff. Furthermore, successful referrals are rewarded accordingly. Hilton also looks for potential management trainees in excellent universities. They will first rotate in various departments, and finally push them to the most suitable management position through assessment.

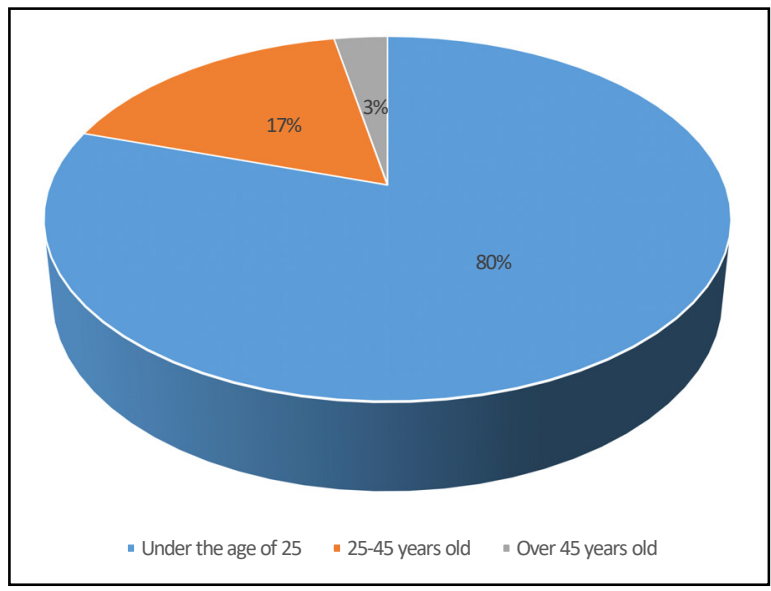

Figure 1. Age structure of Hilton Hotel staff.

As the customers come from different countries, it is possible for diverse and inclusive staff to accurately capture the personalized requirements. Hilton has three criteria for talent selection: focusing on interpersonal communication, the unity of personal and hotel benefits, and paying attention to customers and quality. The hotel belongs to the service industry, so the staff's interpersonal communication ability is particularly important, as well as the first choice of ability assessment criteria. The American Customer Satisfaction Index is a crucial indicator to evaluate the quality of service and customer experience provided by hotels, as well as various aspects of hotel accommodation. Because the selected employees are often better able to meet customer needs, Hilton's customer satisfaction index is maintained at around 80 points all year round, making it one of the best in the hotel industry (Fig. 2).

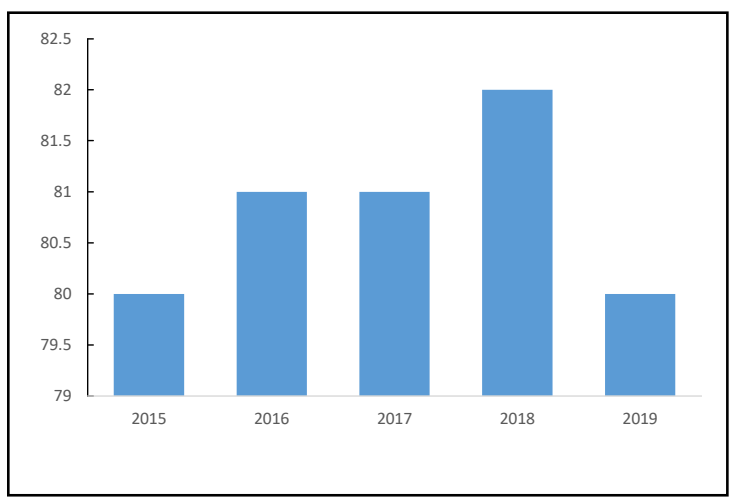

Figure 2. American customer satisfaction index of Hilton Hotel.

Data source: data.iimedia.cn

\section{B. Training and development}

For new employees, Hilton has two different types of training: four hours for entry-level employees, while 40 hours for new management employees, including basic customer service skills and ways to motivate subordinates to improve their service. For department heads, irregular training will be carried out, mainly involving job skills training, corporate culture training, product knowledge training and staff communication skills training.

Hilton Hotel has established a set of characteristic course training system through the Hilton University. Hilton University was founded in 2002, which is not a building or a hotel, but a website that ensures equal learning opportunities for people around the world. There are more than 8,000 free courses on the site, covering topics such as human resources, finance, marketing. The staff can choose courses according to their interests and personal development plans. After the assessment, a performance report will be generated. If the trainees fail the assessment, they can be retaken. But if they fail to pass again, the hotel will consider assigning them to another more suitable position.

\section{Performance management}

Every employee at Hilton is subject to a dynamic, and horizontal performance review, usually conducted on an annual basis and use of the balanced scorecard system. Its efficient performance management includes colleague evaluation, subordinate evaluation, self-evaluation, customer evaluation. Specially, the direct manager of the hotel staff is the main assessor, and their assessment weight accounts for about $2 / 3$ of the total score. For important or highly technical professional positions, peer experts can also be invited to participate to increase the authority of the assessment. The final result of the assessment will determine an annual rating for each employee, which is generally set to five grades: A, B, C, $\mathrm{D}$ and $\mathrm{E}$. 


\section{Pay and benefits}

Base salaries for Hilton Hotel employees are generally above or in line with the industry average, and performance pay is linked to individual competence and job performance. As an important part of the compensation system, benefits are an important means to improve employees' work efficiency and cultivate their loyalty. Employee travel plans are Hilton's most famous talent retention and incentives, employees and their relatives and friends are covered by this plan. They can enjoy the discount on the basis of the most favorable room price, and the discount intensity varies with the employee's working years.

Meanwhile, employee benefits also include the provision of free working meals and accommodation; pay five social insurance and one housing fund; 7 days paid annual leave (increments per year) and so on. In addition to providing employees with a comfortable and relaxed working environment, employees have committees and can set expectations for benefits, which are then followed up by management.

\section{E. Digital information management}

Hilton is one of the early companies in the world to develop hotel information and e-commerce business, its advanced information management system can directly use the data to form management decisions, providing tips for the correction of business strategy. In this way, managers can control the whole situation in fixed areas, reduce unnecessary work tasks, greatly improving their work efficiency, enormously enhancing the scope and depth of management, and flattening the enterprise organization.

\section{F. Expatriate management}

Hilton attaches great importance to cross-cultural training and selects managers who are suitable for the culture of the host country. It not only sends employees for internal training, but also hires professionals for cross-cultural management, so as to avoid the difficulties caused by cultural differences. It mainly involves language training, communication training, cultural training, sensitivity training and adaptability training.

Expatriate managers are required to have a certain understanding of the host country's culture, family support, excellent management and technical skills, good interpersonal skills, overseas work experience, and good personality. There are two types of tests for expatriate managers: the overseas assignment test and the crosscultural value test. In particular, Hilton believes that family factors are significant to the assessment, thus, participants of the acculturation test include both candidates themselves and their families.

\section{HILTON'S LOCALIZATION MANAGEMENT IN CHINA}

The localization management of multinational firms is an irreversible general trend, and the most crucial link is the localization of human resources. Hilton once got off on the wrong foot in the Chinese market, and only opened five hotels between 1988 to 2006. The hotels in Dalian, Shenzhen and other places even announced the termination of the contract. The reason for this was that Hilton still followed the business ideas of the European and American markets, let alone conduct norms through cross-cultural management. When Hilton realized that localization strategy can save labor cost and quickly integrate into local culture and market, Hilton began to change, as well as carry out talent and cultural strategic transformation for the Chinese market.

\section{A.Diversified talent strategy}

Diversity and inclusiveness are the cornerstone of Hilton's talent policy. In southwest China, nearly $40 \%$ of Hilton employees are from 38 ethnic minorities. Hilton has also actively contacted universities in China, and has implemented school enterprise cooperation and industry education integration projects with nearly 400 universities, providing internship and creating talents suitable for China's localization. Students will complete several months of training at the hotel, after which the hotel will evaluate the students' ability, and those who do well will be offered a chance to work at Hilton after graduation. Over the past few years, Hilton has made remarkable progress in localization. It now has more than 27,000 employees in China, and the proportion of local general managers has increased from 55\% in 2016 to $74 \%$ in 2018 .

\section{B.Train female managers}

Hilton realized that Chinese household consumption is usually dominated by women, so the Chinese management of Hilton was determined to make Hilton the best employer brand for women to live, work and grow. To this end, Hilton has used different channels and methods to help the growth of female employees, and has established a mentoring mechanism. Hilton's management team in China has empowered each member of the team to develop a female candidate until she is successfully trained to be an outstanding female general manager. At present, the proportion of female general managers of Hilton in China has reached 20\%, far more than that of other hotels.

\section{C.Festival activities}

Hilton gradually found that there are differences in consumer psychology and preferences between Chinese and western consumers. For example, once the general manager of Hilton Nanjing Hotel, Cade, had some confusion about the Chinese market and asked why Chinese people would ask for a discount after dinner. After further research, Hilton understood that to make ordinary Chinese people be customers, they must know 
their psychology and be close to their needs. As a result, strategies based on China's market conditions have emerged, including launching a series of promotional activities in traditional festivals such as the Spring Festival, Mid-Autumn Festival and national day, and holding various food festivals according to the local market conditions to gather popularity.

\section{D.Flexible management}

Hilton Hotel thinks that if employees are put on one post for a long time, it will inevitably lead to job burnout. On the other hand, due to the characteristics of the hotel industry, for most hotels, the business volume is difficult to avoid in peak season. Therefore, how to use flexible management to avoid the shortage or surplus of human resources became a crucial work of hotel management. Therefore, Hilton has adopted cross training and job rotation mode, and advocated the promotion of senior staff from the grass-roots level. In this way, although the investment in human resources has reduced, the overall staff structure has been optimized.

\section{ENLIGHTENMENT}

The human resource management of transnational hotels will directly or indirectly affect the service quality of hotels, thus affecting the shaping of brand image. As the leader of the global hotel industry, the Hilton Hotel has received satisfactory feedback on its positive measures and strategies in human resource management, which is also worthy of learning and learning from China's multinational hotels. We have summed up the following four aspects.

\section{A.Strengthen the humanistic concept}

From the point of management concept, both the humanistic management and information management can give full play to the enthusiasm and creativity of employees. The pleasant working atmosphere and weakening the hierarchical concept can not only enhance the understanding of employees, but also promote employees to actively provide enthusiastic services to customers and strengthen communication and feedback between different levels.

China's multinational hotels still need to pay attention to the care of employees. While improving the overall quality of employees, they also need to be trained to identify with corporate culture and development goals, to be positive and energetic. As the service industry workers often need to deal with the individual needs and dissatisfaction of customers, it is necessary to create a comfortable and harmonious working environment, relieve the work pressure of employees through group activities or rewards. In terms of digital trends, the purpose of caring for staff can also be achieved by improving the information platform to reduce the workload of relevant personnel and improve the scientific decision-making.
In another way, from the perspective of maintaining the basic interests of employees, hotel managers should build an open two-way communication platform, improve all kinds of formal or informal communication channels, to ensure that every employee has opportunities to give advice. Simultaneously, we suggest collecting opinions through the network to improve the accuracy of information.

\section{B.Improve the quality of training}

From the perspective of the long-term development strategy of the enterprise, attaching great importance to the training of internal employees can integrate the values of employees with the corporate culture, meet the needs of their future career development, and promote the unity of the interests of the company and employees.

At present, the hotel industry of our country still needs to strengthen the optimization of the overall quality and structure of employees, especially to strengthen their interpersonal communication ability of and improve the quality of service. Therefore, training courses should be formulated according to the actual situation of the company, the size of personnel, the company's goals and staff quality, and the training effect should be evaluated to learn about the students' absorption and application of knowledge. These suggestions will help to break down the cultural barriers and role constraints in employees' mind, and enhance their ability to respond and adapt to different environments.

\section{C.Attract and retain talent}

The competition of enterprises, in the final analysis, is the competition of talents. The company needs to have incentive and retention strategies for potential talents, clearly express the value and respect for talents, and expand the scope of brand radiation through online recruitment. Because of this, Hilton is more likely to recruit key talent, but also more loyal and reliable, often willing to carry out their own personal development plan in the hotel.

On the one hand, China's multinational hotels need to create a talent-centered cultural atmosphere. The special treatment for talents should be clearly indicated in the recruitment advertisement, selection and employment are independent of nationality to cultivate and introduce more international management talents. Besides, managers can establish a relatively independent training department, actively strive for school enterprise cooperation, and through the informatization construction of human resource management effectively collect talent resources of various departments to expend their own "talent bank".

On the other hand, focus on attracting talents with special employee benefits, grasping the development status of the company's outstanding staff, and reasonable use of rotation system to overcome the high mobility of hotel employees. Moreover, they should rationally grasp the localization level of human resources, such as gradual transition from grass-roots staff to senior management, so 
as to achieve the goal of encouraging employees to innovate and reducing the rate of brain drain.

\section{D.Promote cultural integration}

Most important, Localization of cultural integration is not simply applying a certain pattern, but constantly colliding and choosing in practice, and then integrating into a new entity, which not only embodies the value of the parent company, but also fully respects the integration of local unique cultural concepts. Multinational companies should have the initiative of localization management, be willing to deeply understand the consumption psychology of customers in host countries, and create characteristics combined with local culture.

If the transnational hotels do not respect the local culture and do not understand the regional differences, they are easy to suffer setbacks. Therefore, in order to make the brand more vitality in the local, China's multinational hotels must respect and enhance the understanding of the cultural consumption mode of the host country, double standards caused by "nationality discrimination" should be strictly avoided. What is more, in order to adapt to the needs of different urban areas as soon as possible, it is a good choice to break the inherent business model and cultivate and trust local managers. At the same time, managers should bear in mind that contradictions and conflicts will inevitably arise in the process of cultural integration, and the company's processing personnel must stand on a neutral point of view to prevent the problem from worsening.

\section{CONCLUSION}

In sum, obtain and retain talent is the key to development, cross-culture management is a significant link and information management is indispensable to promote the sound operation of multinational hotels. When formulating human resource management strategies in the future, Chinese multinational companies should adhere to the people-oriented concept, fully consider the cultural differences of host countries to innovate new means. In the meanwhile, subsidiaries should follow the parent company's main management ideas and development goals, and constantly improve their international adaptability.

\section{ACKNOWLEDGMENT}

We thank the scholars who provided the literature for the study. At the same time, we thank all those who participated in the revision of the paper and their comments have contributed to the improvement of the quality of this paper.

\section{REFERENCES}

1. Hao Shiyu. Human Resources and Cultural Management in Multinational Companies [J]. New Economy,2016(5):1.

2. Zhong He. Hilton: Brand Culture Radiating World [J]. Shopping Mall Modernization,2014(4):36-37.

3. Luo Zhengye. On the choice of human resource management mode of transnational corporations from the perspective of system theory $[\mathrm{J}]$. China management informatization, 2020,23 (12): $107-108$

4. Zhang Shaohui, Gao Aijun. Characteristics and Enlightenment of human resource management of contemporary transnational corporations [J]. Dongyue monograph, 2010,31 (11): 63-65.

5. Zhou Jinbo, Cheng Jing. Research on human resource management strategy of transnational corporations in China [J]. Contemporary economic management, 2014,36 (09): 57-62

6. Li Xuejun, Zhang Jinghui. Hilton: King of Services [J]. Sales and Marketing (Review),2011(5):74-77.

7. Zhong Yihui. People oriented cooperative relationship — on labor relations of some multinational companies in China $[\mathrm{J}]$. Trade union theory and practice. Journal of China Institute of industry and sports, 2004 (4): 77-79.

8. Liu Zhaokun, Lu Shichun. Thinking on the concept of human resource management under the new economic conditions and the enlightenment of the employment mechanism of HP, Hilton and Ford [J]. Economic review, 2000 (11): 46-48.

9. Zhou Zijian, Zou Liang. Research on the development strategy of Dalian Fuli Hilton Hotel Based on SWOT analysis [J]. Business news, 2019 (26): 3-5.

10. Ma Junliang. Research on the development strategy of transnational hotels from the perspective of economic globalization [J]. Frontier, 2012 (12): 110-111.

11. Zhu Mengting. Research on human resource localization strategy of transnational corporations [J]. China business theory, 2016 (34): 55-56.

12. Li Huimin. Comparative analysis of training management system between multinational corporations and state-owned enterprises [J]. Intelligence, 2016 (8): 221-222. 